Izumi, Volume 8 No 1, 2019

e-ISSN: 2502-3535 p-ISSN: 2338-249X

Tersedia online di http://ejournal.undip.ac.id/index.php/izumi

\title{
REPRESENTASI HERO'S JOURNEY PADA TOKOH CHIHIRO DALAM ANIME SPIRITED AWAY KARYA MIYAZAKI HAYAO
}

\author{
Fajria Noviana \\ Fakultas Ilmu Budaya Universitas Diponegoro \\ fajria.noviana@live.undip.ac.id
}

\begin{abstract}
Abstrak
Tulisan ini merupakan hasil dari penelitian kepustakaan berjenis deskriptif kualitatif. Tujuan dari penelitian ini adalah untuk mengungkapkan proses perjalanan kepahlawanan dari tokoh utama anime Spirited Away bernama Chihiro berdasarkan teori Hero's Journey yang dikemukakan oleh Vogler. Data mengenai perjalanan kepahlawanan Chihiro didapatkan dari anime dengan teknik simak-catat. Metode yang digunakan dalam analisis adalah metode analisis konten dengan didasarkan pada teori Hero's Journey. Dari hasil analisis, dapat diketahui bahwa tokoh utama Chihiro telah menjalani secara lengkap keduabelas tahapan perjalanan kepahlawanan. Petualangan Chihiro telah berhasil mengubah kepribadiannya yang awalnya penakut, manja, dan cengeng menjadi pemberani, mandiri, tenang dan percaya diri, serta penuh belas kasih. Proses perjalanan kepahlawanan Chihiro ini membuktikan kebenaran definisi pahlawan menurut Vogler, sekaligus juga membuktikan bahwa untuk memenangkan sebuah 'pertarungan' tidak selalu menggunakan kekuatan fisik. Ada kalanya kecerdasan berpikir dan kecerdasan emosi justru jauh lebih dibutuhkan. Selain menampilkan perjalanan kepahlawanan, anime ini juga banyak menampilkan kamisama yang dahulu dipercayai keberadaannya oleh bangsa Jepang. Miyazaki mungkin ingin mengingatkan kembali mengenai keberadaan para dewa Jepang dengan menampilkan mereka di dalam anime ini, baik yang benar-benar terdapat dalam mitologi Jepang maupun hasil kreasi Miyazaki sendiri. Dengan demikian, kisah Spirited Away yang memiliki struktur mitos seperti yang dikemukakan oleh Vogler menjadi jauh lebih hidup dan menarik.
\end{abstract}

\section{Kata kunci: pahlawan; teori Hero's Journey; anime; analisis konten}

\begin{abstract}
(Title: Representation of Hero's Journey on Main Character Chihiro in Hayao Miyazaki's Spirited Away Anime) This paper is the result of a qualitative descriptive type of literature study. The purpose of this study was to reveal the heroic journey process of main character of Spirited Away anime named Chihiro, based on the Hero's Journey theory proposed by Vogler. Data about Chihiro's heroic journey are obtained from anime with note taking techniques. The method used in the analysis is the method of content analysis based on the theory of Hero's Journey. From the results of the analysis, it can be seen that the main character Chihiro has undergone a total of the twelve stages of the hero's journey. Chihiro's adventure has succeeded in changing her personality which was initially timid, spoiled, and whiny to be brave, independent, calm and confident, and full of compassion. Chihiro's heroic journey proves the true definition of a hero according to Vogler, while also proving that to win a fight does not always use physical strength. There are times when thinking intelligence and emotional intelligence are much more needed. In addition, this anime also features a lot of kamisama which was once believed by the Japanese. Miyazaki might want to remind again about the existence of Japanese gods by displaying them in this anime, either those actually
\end{abstract}


Izumi, Volume 8 No 1, 2019

e-ISSN: 2502-3535 p-ISSN: 2338-249X

Tersedia online di http://ejournal.undip.ac.id/index.php/izumi

found in Japanese mythology or Miyazaki's own creations. Thus, the story of Spirited Away which has a mythical structure as stated by Vogler becomes much more alive and interesting.

Keywords: hero; Hero's Journey theory, anime; content analysis

\section{PENDAHULUAN}

Heroisme tidak hanya dimiliki oleh sosok pahlawan. Heroisme tidak berhubungan dengan usia, kedudukan sosial, atau jenis kelamin. Demikian juga dengan istilah hero dalam teori Hero's Journey yang dikemukakan oleh Christopher Vogler. Vogler tidak menggunakan istilah heroine untuk menyebut sosok pahlawan perempuan secara khusus, seperti umumnya akademisi lain. Menurut Vogler, hero atau pahlawan didefinisikan sebagai berikut.

"Pahlawan adalah seseorang yang bersedia mengorbankan kebutuhan pribadinya demi orang lain, layaknya seorang gembala yang bersedia berkorban untuk melindungi dan mencukupi kebutuhan hewan ternaknya. Pada dasarnya, konsep tentang pahlawan selalu berhubungan dengan pengorbanan diri." (Vogler, 2007, hlm. 29).

Dalam psikologi, arketip dari hero atau pahlawan merepresentasikan apa yang disebut oleh Freud sebagai ego, yaitu bagian dari kepribadian yang menganggap dirinya berbeda dari manusia pada umumnya. Vogler lebih lanjut menyatakan bahwa:

"Ultimately, a Hero is one who is able to transcend the bounds and illusions of the ego, but at first, Heroes are all ego: the I, the one, that personal identity which thinks it is separate from the rest of the group. The journey of many Heroes is the story of that separation from the family or tribe, equivalent to a child's sense of separation from the mother." (Vogler, 2007, hlm. 29).

Kutipan di atas menyatakan bahwa perjalanan dari banyak tokoh pahlawan sebenarnya merupakan perpisahan para tokoh pahlawan tersebut dari keluarganya atau kelompoknya, yang dapat dianggap sejenis dengan perpisahan seorang anak dari ibunya. Hal ini menjadi salah satu alasan penggunaan teori Hero's Journey yang dikemukakan oleh Vogler untuk meneliti mengenai perjalanan kepahlawanan Chihiro, seorang anak perempuan yang menjadi tokoh utama dalam anime berjudul Spirited Away karya Miyazaki Hayao.

Spirited Away adalah judul yang digunakan oleh Walt Disney Pictures untuk memasarkan anime ini ke luar Jepang, yang mencakup wilayah Amerika, Eropa, dan Asia. Anime produksi Studio Ghibli tahun 2001 ini memiliki judul asli 千と千尋の神隠し(Sen to Chihiro no Kamikakushi) yang berarti 'Sen dan Chihiro yang disembunyikan oleh para dewa atau arwah'. Dalam tulisannya, Staemmler menjelaskan kamikakushi sebagai:

"a term from the wide area of Japanese folk belief explaining the sudden and mysterious disappearance of individuals as their abduction by supernatural beings." (Staemmler, 2016, hlm. 342)

Anime ini bercerita tentang perjuangan seorang anak perempuan bernama Chihiro untuk menyelamatkan ayah dan ibunya yang dikutuk menjadi babi oleh seorang penyihir, saat tanpa sengaja keluarga mereka masuk ke dalam dunia para arwah.

Tujuan dari penelitian ini adalah untuk mengungkapkan proses pembentukan pahlawan dari tokoh utama anime Spirited Away bernama Chihiro berdasarkan teori Hero's Journey milik Christopher Vogler. Tokoh utama Chihiro adalah seorang anak perempuan yang masih duduk di bangku Sekolah Dasar. Pada bagian awal anime, ia ditampilkan sebagai tokoh yang bersifat penakut, manja, dan cengeng. Namun, 
setelah menghadapi berbagai peristiwa yang mengancam hidupnya dan kedua orangtuanya, Chihiro berubah menjadi seorang anak perempuan yang pemberani, mandiri, tenang dan percaya diri, serta penuh belas kasih.

Terdapat beberapa tulisan yang menggunakan teori Hero's Journey yang dikemukakan oleh Vogler untuk menganalisis proses perubahan seorang tokoh dari 'bukan siapa-siapa' menjadi orang yang diperhitungkan kehadirannya, atau seringkali disebut dengan ungkapan 'from zero to hero'. Meskipun demikian, teori Hero's Journey yang digunakan sebagai dasar untuk melakukan analisis umumnya bersumber dari teori milik Joseph Campbell. Sedikit berbeda dengan Campbell yang membagi proses from zero to hero-nya ke dalam tujuh belas tahapan (Campbell, 2004, hlm. 45-226), Vogler menyederhanakan tahap-tahap perjalanan kepahlawanannya dan tidak menganggap semua tahapan tersebut sebagai sesuatu yang wajib ada.

Sebagai contoh pertama adalah artikel jurnal berjudul On Damsels and Heroines: A Comparative Study of the Hero's Journey in Little Red Riding Hood and Freeway yang mencari tahu mengenai berhasil atau tidaknya perjalanan kepahlawanan tokoh utama dalam dongeng Little Red Riding Hood dan film Freeway yang merupakan versi adaptasi dari dongeng Little Red Riding Hood tersebut. Simpulan yang disampaikan dalam artikel yang mendasarkan pada teori Hero's Journey milik Campbell tersebut menyatakan bahwa tokoh gadis kecil dalam dongeng Little Red Riding Hood tidak berhasil menjadi seorang pahlawan. Sebaliknya, tokoh utama dalam film Freeway berhasil membunuh serigala jahat dan tampil sebagai pahlawan. Hal ini disebabkan oleh setting patriarkisme yang cukup kental dalam dongeng Little Red Riding Hood, namun tidak demikian dalam film Freeway (Nouri, 2018).

Sementara, artikel yang khusus membahas perjalanan kepahlawanan tokoh
Chihiro dalam anime Spirited Away dengan menggunakan teori Hero's Journey milik Vogler tidak ditemukan. Namun terdapat beberapa artikel yang menggunakan objek kajian anime Spirited Away. Sebagai contoh adalah artikel berjudul Innocence as a Super-power: Little Girls on the Hero's Journey. Artikel ini menyoroti kekuatan karakter tiga gadis kecil dalam tiga film, yaitu Dorothy dalam The Wizard of $\mathrm{Oz}$, Lucy dalam Narnia, dan Chihiro dalam Spirited Away. Dari ketiga karakter ini, ternyata Chihiro menjadi tokoh yang paling banyak menunjukkan peningkatan kualitas mentalnya (Emerson, 2009).

\section{METODE}

Penelitian ini merupakan penelitian kepustakaan berjenis deskriptif kualitatif. Data mengenai perjalanan kepahlawanan tokoh Chihiro diambil dari anime berjudul Sen to Chihiro no Kamikakushi dengan teknik simak-catat. Metode yang digunakan dalam analisis adalah metode analisis konten dengan didasarkan pada teori Hero's Journey yang dikemukakan oleh Christopher Vogler. Teori ini dipilih selain karena memiliki kesesuaian dalam hal tahapan perjalanan kepahlawanan dengan perjuangan Chihiro, teori ini juga memuat struktur mitos yang merupakan inti dari kisah yang menarik (Allison, Goethals, \& Kramer, 2017, hlm. xxi).

\section{Sinopsis}

Chihiro adalah anak perempuan berusia sepuluh tahun yang harus mengikuti orangtuanya berpindah tempat tinggal ke kota lain. Chihiro tidak senang dengan perpindahan itu, sehingga sepanjang perjalanan menuju rumah barunya ia terlihat melamun dan murung. Ia juga mengeluhkan buket bunga pertama yang ia terima dalam hidupnya adalah hadiah perpisahan dari teman-teman sekelasnya. Buket bunga dengan kartu ucapan bertuliskan namanya itu sudah mulai layu dan kelopaknya pun mulai rontok. 
Ayah Chihiro yang mengemudikan mobil mengambil jalan pintas agar mereka cepat sampai, tetapi ternyata tanpa sadar mereka justru masuk ke dunia para arwah, setelah ayah Chihiro memarkir mobil di ujung jalan buntu dan berjalan melintasi padang rumput. Ayah dan ibu Chihiro kemudian asyik menyantap berbagai hidangan lezat yang tersedia di warungwarung makanan yang berjejer di sepanjang jalan desa di dunia para arwah tersebut, meskipun Chihiro sudah mengingatkan mereka untuk tidak memakannya karena tidak nampak seorang pun di semua warung yang ada.

Ketika orangtuanya sedang asyik melahap berbagai hidangan, Chihiro menyusuri jalan desa tersebut dan sampai di sebuah jembatan besar yang menuju rumah pemandian umum yang sangat besar. Di jembatan itu ia bertemu Haku, seorang anak laki-laki yang terlihat sebaya dengannya. Haku meminta Chihiro dan keluarganya segera meninggalkan tempat itu sebelum senja datang, namun ternyata sudah terlambat. Ayah dan ibu Chihiro yang tadinya melahap berbagai hidangan di warung dengan rakusnya telah berubah menjadi babi yang sangat besar dan tidak mengenali Chihiro. Para arwah berupa bayangan hitam besar yang menjadi penduduk desa itu pun mulai menampakkan diri. Chihiro yang ketakutan melihat hal tersebut kemudian berusaha kembali ke mobilnya, namun ia terhalang oleh padang rumput yang telah berubah menjadi lautan. Tubuh Chihiro pun ternyata lambat laun memudar, sehingga ia tetap bisa melihat meskipun sudah menutup mata dengan kedua tangannya.

Karena ketakutan dan putus asa, Chihiro bersembunyi di salah satu sudut desa sambil menangis. Saat itulah, Haku datang menolong dan memberi Chihiro sebutir buah beri untuk dimakan, agar tubuh Chihiro kembali normal. Haku lalu memberitahu agar Chihiro bekerja untuk Yubaba, penyihir yang memiliki rumah pemandian umum di dunia para arwah tersebut. Dengan demikian, Chihiro memiliki kesempatan untuk menolong kedua orangtuanya yang dikutuk menjadi babi oleh Yubaba.

Sepanjang petualangan Chihiro di dunia para arwah tersebut, ia banyak dibantu tidak hanya oleh Haku, namun juga oleh Kamaji dan Rin. Kamaji adalah siluman laba-laba berwujud kakek tua yang memiliki enam tangan sangat panjang, yang dapat memanjang sampai beberapa meter, dan dua kaki. Sementara, Rin adalah hantu berwujud gadis muda yang cukup cantik. Selain ketiga tokoh ini, terdapat juga tokoh Kaonashi dan Bou yang kehadirannya cukup signifikan dalam anime ini. Kaonashi adalah hantu berwujud bayangan hitam yang tidak memiliki wajah, sehingga ia selalu mengenakan topeng. Sedangkan Bou adalah bayi berukuran raksasa, anak dari penyihir Yubaba. Satu tokoh lagi yang hanya muncul di perempat akhir cerita adalah Zeniba, saudara kembar Yubaba yang juga seorang penyihir, yang memberikan jimat berupa ikat rambut kepada Chihiro agar ia terhindar dari pengaruh Yubaba.

Chihiro yang kemudian diterima bekerja oleh Yubaba di rumah pemandian umum tersebut sempat melupakan jati dirinya, setelah namanya diubah oleh Yubaba menjadi Sen. Ternyata, itu adalah cara Yubaba untuk membuat siapapun yang bekerja untuknya tunduk dan tidak bisa meninggalkan tempat itu untuk selamanya.

Chihiro menempuh berbagai rintangan dan ujian yang mengancam keselamatan dirinya di dunia para arwah, demi menyelamatkan kedua orangtuanya dan Haku. Haku ternyata adalah dewa sungai Kohaku yang pernah menyelamatkan Chihiro yang dahulu pernah terjatuh ke sungai Kohaku saat masih kanak-kanak. Sayangnya, sungai Kohaku telah lama dikeringkan untuk pembangunan perumahan, sehingga Haku tidak punya tempat untuk kembali. Pada akhir cerita, Chihiro berhasil menyelamatkan Haku dan 
Izumi, Volume 8 No 1, 2019

e-ISSN: 2502-3535 p-ISSN: 2338-249X

Tersedia online di http://ejournal.undip.ac.id/index.php/izumi

kedua orangtuanya. Chihiro pun lalu kembali ke dunia manusia bersama ayah dan ibunya (Miyazaki, 2001).

\section{LANDASAN TEORI}

Mitos merupakan satu bagian kisah dari mitologi. Menurut Abrams dalam buku A Glossary of Literary Terms, istilah mitos dapat dimaknai sebagai:

“...a system of hereditary stories of ancient origin which were once believed to be true by a particular cultural group, and which served to explain (in terms of the intentions and actions of deities and other supernatural beings) why the world is as it is and things happen as they do." (Abrams, 1999, hlm. 170).

Abrams juga menambahkan bahwa:

"The term "myth" has also been extended to denote supernatural tales that are deliberately invented by their authors." (Abrams, 1999, hlm. 171).

Dalam Spirited Away, Miyazaki Hayao menampilkan cukup banyak kamisama atau dewa di dalam dunia para arwah yang dimasuki Chihiro dan kedua orangtuanya tanpa sengaja ini. Para dewa yang sangat banyak jumlah dan macamnya ini disebut yaoyorozu no kamigami, yang berarti 'delapan juta dewa'. Angka ini hanyalah untuk menunjukkan jumlah yang sangat banyak, bukan menunjukkan jumlah pasti keseluruhan dewa di Jepang. Ashkenazi menyatakan bahwa umumnya dewa-dewa ini tidak memiliki nama. Sebagian bahkan hanya disembah di kuilkuil Shinto lokal. Hal ini menunjukkan bahwa kami, baik yang dikenal maupun tidak, telah meresap ke dalam kehidupan bangsa Jepang. Ia juga menambahkan bahwa:

"This idea is related to the concept that Japan is eminently the land of the kami, and therefore that the boundaries between the Japanese, as a people, and their kami are multistranded." (Ashkenazi, 2003, hlm. 291)

Teori Hero's Journey yang dikemukakan oleh Vogler memiliki dua belas tahap yang menunjukkan perubahan seorang tokoh dari yang 'bukan siapa-siapa' menjadi seseorang yang diperhitungkan kehadirannya. Kedua belas tahap tersebut dijelaskan secara singkat sebagai berikut (Vogler, 2007, hlm. 83-227).

1. Ordinary World

Merupakan tempat asal atau situasi awal dari seorang pahlawan yang menjadi latar belakang kehidupannya.

2. Call to Adventure

Merupakan tahap seleksi seorang pahlawan melalui ketidakstabilan situasi dalam lingkungan (masyarakat). Pada saat-saat demikian, seseorang dapat muncul dan mengajukan diri secara sukarela untuk mengatasi ketidakstabilan situasi tersebut, atau terpilih/dipilih untuk bertanggung jawab. Pada tahap inilah seorang pahlawan harus menghadapi awal perubahan.

3. Refusal of the Call

Merupakan usaha untuk menghindar dari petualangan sebagai reaksi awal. Reaksi ini umumnya timbul setelah pahlawan mengetahui resiko dari petualangan yang harus dihadapinya. Penolakan terhadap petualangan ini mungkin hanya berupa satu atau dua patah kata yang menunjukkan kebimbangan pahlawan.

4. Meeting with the Mentor

Merupakan tahap pertemuan pahlawan dengan seseorang yang melindungi, memberi bantuan atau benda tertentu, latihan, atau saran yang dapat membantu pahlawan dalam petualangannya. Tokoh mentor juga dapat berwujud pengalaman dari tokoh yang telah tiada, atau bahkan kebijakan yang ditemukan dalam diri pahlawan itu sendiri.

5. Crossing the First Threshold 
Merupakan aktifitas pahlawan memasuki wilayah atau situasi baru yang berbeda dengan wilayah atau situasi sebelumnya dan belum dikenal oleh pahlawan. Aktifitas ini umumnya didahului oleh adanya tekanan dari luar yang membuat pahlawan melewati gerbang pertama untuk memasuki wilayah baru dan memulai petualangannya. Gerbang tersebut memiliki penjaga atau threshold guardian yang dapat berwujud mahluk hidup atau benda mati, kondisi lingkungan, bahkan derita atau ketakutan dalam diri pahlawan itu sendiri.

6. Tests, Allies, Enemies

Merupakan tahap untuk menguji pahlawan sebagai persiapan sebelum memasuki tahap berikutnya. Pada tahap ini pula, pahlawan bertemu dengan sekutu dan musuh.

7. Approach to the Inmost Cave

Merupakan tahap persiapan bagi pahlawan dan sekutunya untuk menghadapi tantangan utama.

8. The Ordeal

Merupakan tahap cobaan di bagian pertengahan cerita yang membuat pahlawan harus berhadapan dengan tantangan terberat atau ketakutan terbesarnya. Dalam tahap ini, pahlawan nyaris atau bahkan harus mati dan dilahirkan kembali, baik secara tersurat maupun tersirat.

9. Reward

Merupakan tahap dimana pahlawan memperoleh harta atau sesuatu yang berharga, yang ia dapatkan setelah menghadapi kematian. Meskipun demikian, resiko kehilangan kembali harta tersebut masih dimungkinkan.

10. The Road Back

Merupakan bagian perempat akhir cerita yang menjadi tahap dimana pahlawan didorong untuk menyelesaikan petualangan. Dalam tahap ini sering muncul adegan pengejaran yang menunjukkan seberapa penting dan berbahayanya misi tersebut.

11. The Resurrection

Merupakan tahap untuk menguji pahlawan sekali lagi. Berkat tindakan berani pahlawan, konflik yang muncul di awal cerita dapat diselesaikan. Dalam tahap ini, perubahan kepribadian pahlawan terlihat nyata.

12. Return with the Elixir

Merupakan tahap kepulangan pahlawan ke tempat asalnya atau melanjutkan petualangannya, dengan membawa harta atau sesuatu yang berharga yang memiliki kekuatan untuk mengubah dunia, sebagaimana halnya harta tersebut telah mengubah sang pahlawan.

Vogler menyatakan bahwa tahaptahap Hero's Journey seperti disebutkan di atas tidaklah baku, karena pengarang memiliki kebebasan untuk mengubahnya agar sesuai dengan yang diinginkan atau disesuaikan dengan kebutuhan dari kebudayaan tertentu, seperti disebutkan dalam kutipan berikut:

"I'm retelling the hero myth in my own way, and you should feel free to do the same. Every storyteller bends the mythic pattern to his or her own purpose or the needs of a particular culture." (Vogler, 2007, hlm. 7)

Dengan demikian, keduabelas tahapan perjalanan kepahlawanan dalam teori ini hanya merupakan acuan, bukan sebagai sesuatu yang mutlak ada.

\section{HASIL DAN PEMBAHASAN}

Hasil analisis berikut pembahasannya di bawah ini dibagi ke dalam dua belas subbab sesuai dengan pembagian tahap perjalanan kepahlawanan dari teori Hero's Journey.

\section{Ordinary World}

Merupakan tahap perkenalan tokoh yang ditunjukkan dengan perjalanan Chihiro dan kedua orangtuanya 
menggunakan mobil menuju tempat tinggal baru di kota lain. Chihiro terlihat murung, melamun, dan sering mengeluh. Ia menampakkan sifat penakutnya saat melihat tumpukan rumah-rumah kecil dari batu untuk para dewa yang tergeletak tak beraturan di tepi jalan.

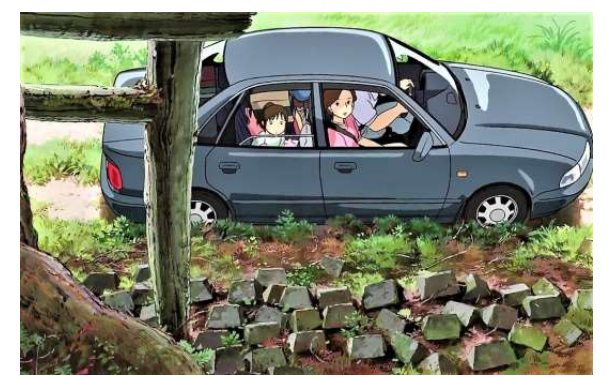

Gambar 1. Chihiro memandangi rumah-rumah batu kecil untuk kamisama dengan takut Sumber: Spirited Away (00:02:10)

\section{Call to Adventure}

Jalan buntu yang mereka temui dalam perjalanan ternyata berujung pada bangunan yang memiliki terowongan sempit dan gelap. Chihiro merasakan hembusan angin dari dalam terowongan yang seolah-olah menyedotnya masuk. Chihiro sebenarnya enggan masuk ke dalam terowongan itu, tapi karena ayah dan ibunya bersikeras untuk mencari tahu apa yang ada di ujung terowongan, ia pun terpaksa mengikuti mereka karena ia takut berada di dalam mobil sendirian.

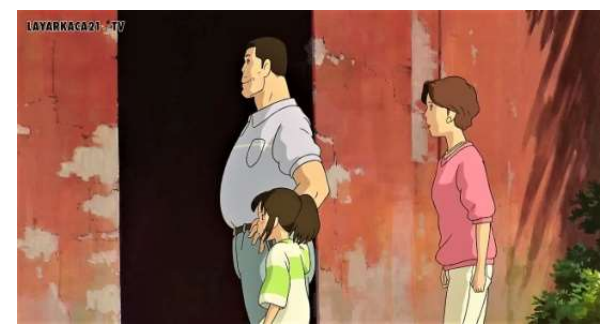

Gambar 2. Chihiro dan ayah ibunya tiba di bangunan dengan terowongan sempit dan gelap Sumber: Spirited Away (00:03:46)
Ternyata, di ujung terowongan terhampar padang rumput yang luas. Di seberang padang rumput, terlihat beberapa bangunan rumah. Mereka bertiga kemudian mendatangi rumahrumah yang nampak di seberang padang rumput. Tanpa mereka ketahui, terowongan tersebut sebenarnya merupakan gerbang penghubung antara dunia manusia dengan dunia arwah.

\section{Refusal of the Call}

Bau harum hidangan yang tertata rapi di warung-warung yang berjajar di sepanjang desa telah membuat ayah dan ibu Chihiro dengan berani melahapnya dalam jumlah yang sangat banyak, meskipun tidak ada seorang pun di warung tersebut. Mereka tidak mengetahui bahwa hidangan-hidangan tersebut disiapkan untuk para arwah yang akan segera datang ke dunia para arwah tersebut selepas senja. Akibatnya, mereka berubah menjadi babi yang sangat besar dan lupa akan jati diri mereka sebagai manusia.

Melihat hal tersebut, Chihiro yang menolak ketika diajak untuk ikut memakan hidangan tersebut oleh ayah dan ibunya merasa sangat takut. Ditambah dengan munculnya penduduk desa berwujud bayangan hitam besar yang sangat banyak membuat Chihiro berusaha kembali ke mobil mereka secepat mungkin (Spirited Away, 00:12:46).

\section{Meeting with the Mentor}

Dalam anime ini, tokoh pahlawan Chihiro memiliki beberapa mentor seperti dijelaskan berikut ini.

\subsection{Haku}

Haku adalah anak laki-laki yang terlihat sebaya dengan Chihiro, namun sebenarnya ia adalah dewa sungai Kohaku yang bernama Nigihayami Kohaku-nushi. Haku membantu Chihiro dalam banyak kesempatan yang dapat dibagi ke dalam tiga kelompok waktu, yaitu saat berada di 
Izumi, Volume 8 No 1, 2019

e-ISSN: 2502-3535 p-ISSN: 2338-249X

Tersedia online di http://ejournal.undip.ac.id/index.php/izumi

dunia manusia, saat berada di dunia para arwah sebelum bertemu Yubaba, dan saat berada di dunia para arwah setelah bertemu Yubaba.

Saat berada di dunia manusia menjadi kali pertama Haku menyelamatkan Chihiro. Ini terjadi saat Chihiro terjatuh ke dalam sungai Kohaku saat masih kanak-kanak.

Kemudian, saat Chihiro berada di dunia para arwah sebelum bertemu Yubaba, Haku beberapa kali membantunya. Pertama, saat Chihiro berada di jembatan besar penghubung desa dengan rumah pemandian umum milik Yubaba menjelang senja, Haku memperingatkannya agar segera kembali ke dunia manusia. Kedua, Haku memberikan buah beri sebagai penawar agar tubuh Chihiro tidak memudar karena berada di dunia para arwah setelah senja datang. Ketiga, membantu Chihiro menyeberangi jembatan menuju rumah pemandian umum, tempat yang relatif lebih aman daripada desa para arwah. Keempat, memberitahu Chihiro untuk menemui Kamaji dan meminta bantuannya untuk mendapat atau diberi pekerjaan.

Berikutnya, saat Chihiro berada di dunia para arwah setelah bertemu Yubaba, Haku pun beberapa kali membantunya. Pertama, Haku mengantarkan Chihiro untuk memulai pekerjaan di rumah pemandian umum setelah diterima bekerja oleh Yubaba. Kedua, menunjukkan kandang tempat orangtua Chihiro yang berubah menjadi babi dipelihara. Ketiga, memberi onigiri kepada Chihiro yang belum makan apapun sejak tanpa sengaja memasuki dunia para arwah, kecuali sebutir kecil buah beri dari Haku. Keempat, menjemput Chihiro yang berada di rumah Zeniba untuk mengembalikan cap magis milik Zeniba yang diambil Haku, untuk kembali ke tempat Yubaba dan menyelamatkan kedua orangtua Chihiro.

\subsection{Kamaji}

Kamaji bekerja di rumah pemandian umum sebagai pembuat ramuan herbal untuk pembersih tubuh pelanggan yang datang dan untuk membersihkan bak mandi setelah digunakan berendam. Penampilan Kamaji sebagai siluman laba-laba memang menakutkan, namun sebenarnya ia memiliki hati yang baik. Hal ini terbukti dari beberapa kali Kamaji menyelamatkan Chihiro.

Pertama, saat Rin terkejut karena melihat ada anak manusia di ruang kerja Kamaji, Kamaji mengakui Chihiro sebagai cucunya. Kedua, Kamaji meminta tolong kepada Rin untuk mengantarkan Chihiro menemui Yubaba. Ketiga, atas permintaan Chihiro, Kamaji membantu merawat Haku yang terluka parah. Keempat, memberikan tiket kereta sekali jalan kepada Chihiro untuk pergi ke rumah Zeniba, agar ia dapat mengembalikan cap magis Zeniba yang dicuri oleh Haku atas perintah Yubaba.

\subsection{Rin}

Rin adalah hantu gadis muda yang bekerja di rumah pemandian umum. Ia sangat cekatan dalam mengerjakan berbagai tugas yang diberikan kepadanya. Sebagai seorang yang cukup senior, Rin mengajarkan kepada Chihiro hal-hal yang perlu diketahui dan dikuasai oleh pekerja rumah pemandian umum. Rin pun menyiapkan pakaian kerja untuk Chihiro, mengambilkannya jatah makan, dan menemaninya mengobrol sebagai rutinitas harian. Selain itu, Rin banyak membantu saat Chihiro diberi tugas untuk melayani tamu yang berbau sangat busuk dan sangat susah untuk dibersihkan.

Rin bahkan menyelamatkan nyawa Chihiro saat Chihiro dikejar-kejar oleh Kaonashi yang berubah menjadi rakus dan tak terkendali di dalam rumah 
pemandian umum. Rin menjemput Chihiro yang terjun ke dalam laut dengan menggunakan perahu dayung kecil. Rin kemudian mengantarkan Chihiro ke stasiun kereta terdekat yang terletak di permukaan air agar ia dapat pergi ke rumah Zeniba.

\subsection{Dewa Sungai}

Selain Haku, terdapat seorang dewa sungai lain yang berusia ratusan tahun dan berwujud naga putih besar dan sangat panjang, yang memiliki wajah kakek tua. Dewa sungai ini menolong Chihiro yang tenggelam dalam lumpur yang berasal dari tubuhnya saat ia mandi di rumah pemandian umum milik Yubaba.

Kemudian, sebagai hadiah karena Chihiro telah berhasil membersihkan tubuhnya, dewa sungai ini memberikan sebutir besar obat herbal. Setengah dari obat ini kemudian diberikan Chihiro kepada Haku yang terluka parah dan setengah lagi diberikan kepada Kaonashi yang berubah menjadi rakus dan tak terkendali jika berada di dalam rumah pemandian umum.

\subsection{Zeniba}

Zeniba adalah saudara kembar identik Yubaba. Meskipun merupakan saudara kembar, tetapi ternyata mereka berdua bermusuhan. Namun, kedatangan Chihiro ke rumah Zeniba telah melunakkan hatinya. Ia pun kemudian menenunkan ikat rambut magis untuk Chihiro, agar Chihiro tidak lagi terpengaruh oleh sihir dan tipu daya Yubaba.

\section{Crossing the First Threshold}

Keinginan kuat Chihiro untuk menyelamatkan kedua orangtuanya telah memberinya keberanian untuk memasuki rumah pemandian umum milik Yubaba. Agar aman, ia harus masuk melalui ruang bawah tanah. Namun, untuk mencapai ruang bawah tanah tersebut dari luar rumah pemandian, Chihiro harus menuruni ratusan anak tangga kayu rapuh yang terletak di tebing batu tanpa pegangan dan alat bantu sama sekali. Anak tangga kayu ini berperan sebagai threshold guardian. Meskipun dipenuhi rasa takut dan bahkan nyaris terjatuh dari ketinggian setelah salah satu anak tangga yang diinjaknya patah, Chihiro akhirnya berhasil menuruni ratusan anak tangga tersebut dengan selamat.

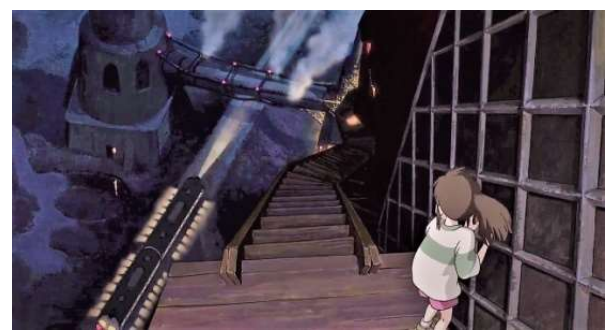

Gambar 3. Chihiro memberanikan diri menuruni ratusan anak tangga Sumber: Spirited Away (00:20:51)

\section{Tests, Allies, Enemies}

Chihiro kemudian memberanikan diri menemui Kamaji yang sedang meramu obat herbal di ruang kerja bawah tanah. Kamaji dalam hal ini bertindak sebagai sekutu dan bahkan mentor Chihiro. Rin yang datang untuk memberikan jatah makan bagi Kamaji dan para susuwatari yang menjadi pembantu Kamaji kemudian mengantarkan Chihiro untuk menemui Yubaba, atas permintaan Kamaji. Susuwatari adalah arwah berwujud gumpalan jelaga hitam seukuran kepalan tangan anak-anak, berbentuk mirip buah rambutan, berpindah tempat dengan cara melayang, serta memiliki tangan dan kaki yang digunakan saat bekerja mengangkut bongkahan batubara. Susuwatari ini bertindak sebagai sekutu, sedangkan Rin bertindak sebagai sekutu sekaligus mentor.

Chihiro kemudian berhasil menemui Yubaba di ruang kerjanya dan membuat Yubaba bersedia mempekerjakan dirinya, meskipun sebelumnya Yubaba marah karena kelancangan Chihiro yang berani 
memasuki rumah pemandian umum di dunia para arwah, tempat yaorozu no kamigami melepas lelah setelah bekerja (Spirited Away, 00:36:40). Setelah menandatangani kontrak kerja dengan Yubaba, nama Chihiro dalam surat kontrak tersebut diubah Yubaba dengan cara dibuang dan hanya disisakan satu huruf kanji dari nama lengkap Ogino Chihiro, yang menjadi hanya satu huruf kanji yaitu Sen, seperti gambar berikut.

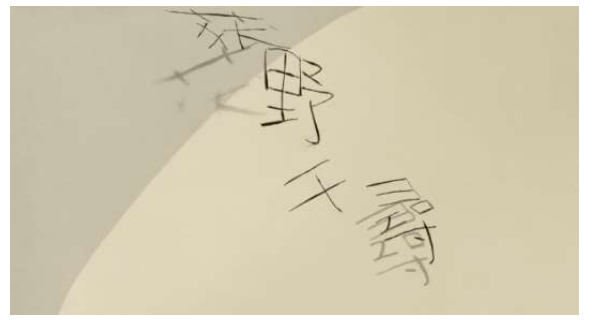

Gambar 4. Yubaba membuang huruf kanji nama Chihiro dan menjadi Sen

Sumber: Spirited Away (00:40:17)

Sepanjang kisah dalam anime ini, Yubaba terus berperan sebagai musuh Chihiro. Dalam satu kesempatan, ia memberikan tugas kepada Chihiro untuk melayani pelanggan yang berbau sangat busuk dan menyengat. Namun, berkat bantuan Kaonashi yang secara diam-diam mengambilkan obat herbal terbaru dan terbaik, Chihiro pun berhasil membuat pelanggan yang ternyata dewa sungai menjadi puas, karena tubuhnya kembali menjadi putih bersih. Dari peristiwa ini, dapat dikatakan bahwa Kaonashi telah menjadi sekutu Chihiro dalam tes yang dihadapinya.

\section{Approach to the Inmost Cave}

Saat Chihiro berusaha menghindari Yubaba, ia bersembunyi di bawah tumpukan bantal di kamar tidur Bou, bayi raksasa anak Yubaba. Tanpa diduga, Bou yang ternyata juga berada dalam tumpukan bantal tersebut menangkapnya dan mengancam akan mematahkan tangan Chihiro yang kurus jika ia tidak mau menemani Bou bermain. Namun Chihiro berhasil melepaskan diri. Pertemuan dengan Bou ini menjadi 'goa terdalam' bagi Chihiro.

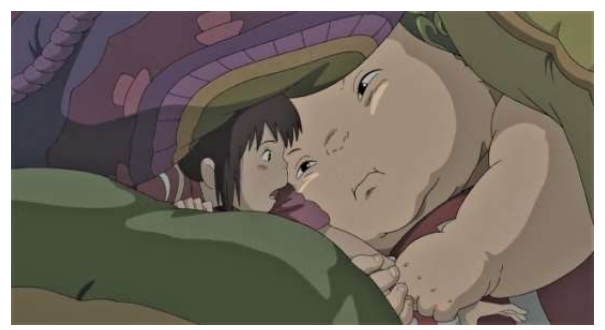

Gambar 5. Chihiro ditangkap Bou Sumber: Spirited Away (01:20:40)

Saat Bou mulai menangis, muncullah bayangan Zeniba yang sama persis dengan Yubaba hingga Bou mengira itu adalah ibunya. Zeniba kemudian mengubah Bou menjadi seekor tikus gendut yang lucu agar ia lebih lincah bergerak, tidak hanya berbaring di kamar setiap saat. Mulai saat itulah, Bou berubah menjadi sekutu Chihiro dan membela Chihiro saat akan diperlakukan tidak adil oleh Yubaba. Sementara, Zeniba berperan sebagai sekutu sekaligus mentor bagi Chihiro.

\section{The Ordeal}

Di lantai ruang kerja Yubaba terdapat sebuah lubang tersembunyi yang cukup besar. Lubang ini mengarah ke bawah tanah yang di dasarnya terdapat banyak arwah jahat yang akan memakan apapun yang terjatuh ke sana. Biasanya, apapun yang terjatuh ke dalam lubang tersebut tidak akan bisa kembali dengan selamat.

Haku yang sedang pingsan karena terluka parah dengan mudah dijatuhkan ke dalam lubang tersebut oleh para pembantu Yubaba. Chihiro berusaha memeganginya, tetapi akhirnya ia pun ikut terjatuh bersama Haku dan Bou. 


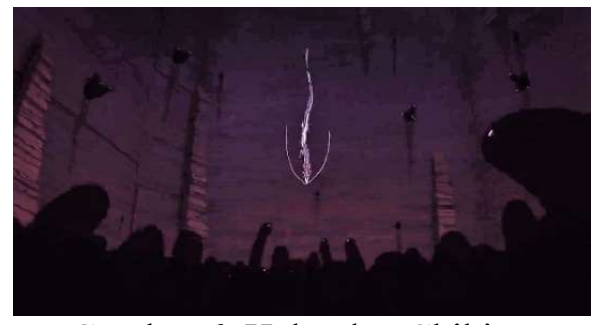

Gambar 6. Haku dan Chihiro jatuh ke dalam lubang penuh arwah pemangsa

Sumber: Spirited Away (01:25:25)

Beruntung, Haku yang sedang berada dalam wujud naga putih saat pingsan karena luka parah dan dijatuhkan ke lubang berhasil diselamatkan Chihiro dan dibawa ke ruang kerja Kamaji. Peristiwa ini menunjukkan near death experience bagi Chihiro, baik secara fisik maupun psikis. Secara fisik karena tubuhnya ikut terjatuh bersama Haku dan nyaris menjadi mangsa arwah-arwah yang ada di dasar goa. Secara psikis karena kondisi Haku sangat kritis, padahal hanya kepada Haku-lah Chihiro menggantungkan harapan untuk menyelamatkan ayah dan ibunya. Peristiwa near death experience ini merupakan sesuatu yang biasanya dialami oleh pahlawan dalam petualangannya.

\section{Reward}

Bersamaan dengan selamatnya Haku, cap magis milik Zeniba yang dicuri Haku atas perintah Yubaba berhasil ditemukan. Chihiro kemudian pergi ke rumah Zeniba bersama Bou dan Kaonashi untuk mengembalikan cap magis tersebut, sekaligus memohonkan maaf untuk Haku atas perbuatannya. Zeniba yang tersentuh melihat kebaikan hati Chihiro kemudian menenunkan ikat rambut yang ia beri mantera, agar Chihiro terhindar dari tipu daya dan pengaruh sihir Yubaba.

\section{The Road Back}

Haku yang sudah pulih datang menjemput Chihiro dan Bou untuk diajak menemui Yubaba untuk mematahkan kutukan terhadap orangtua Chihiro dan menghapus kontrak kerja Chihiro di rumah pemandian umum. Yubaba bersedia melakukan hal tersebut karena ia beranggapan bahwa Bou diculik oleh Chihiro. Padahal, sebenarnya Bou yang berubah wujud menjadi tikus gemuk dengan suka cita mengikuti Chihiro, bahkan bermanja-manja dengan naik ke pundak Chihiro.

Dalam perjalanan kembali ke rumah pemandian umum dengan menaiki Haku yang berwujud naga putih, Chihiro yang sudah memakai ikat rambut bermantera dari Zeniba teringat bahwa dirinya saat masih kanak-kanak pernah terjatuh ke dalam sungai Kohaku, lalu ia menceritakannya pada Haku. Mendengar cerita tersebut, saat itu juga Haku teringat akan jati dirinya, yaitu dewa sungai Kohaku bernama Nigihayami Kohaku-nushi. Saat itu pula seluruh sisik di tubuh Haku terlepas. Hal ini menandakan bahwa Yubaba sudah tidak memiliki kuasa apapun terhadap Haku. Haku pun kembali kepada jati dirinya, meskipun sayangnya ia tidak bisa kembali ke tempat tinggalnya semula, yaitu sungai Kohaku. Hal ini disebabkan oleh telah dikeringkannya sungai Kohaku untuk pendirian perumahan di lokasi sungai tersebut.

\section{The Resurrection}

Kedatangan Chihiro, Haku, dan Bou ternyata telah ditunggu-tunggu oleh Yubaba bersama beberapa ekor babi di ujung jembatan. Saat itu, Yubaba baru mengetahui jika tikus gemuk yang bersama Chihiro adalah Bou, saat Bou merubah tubuhnya menjadi bayi raksasa kembali.

Dengan kepribadian barunya yang pemberani, mandiri, dan penuh kasih 
sayang, Chihiro mendekati Yubaba dengan wajah tersenyum, bahkan memanggilnya dengan sebutan obaachan atau 'nenek'.

Yubaba kemudian memberi hanya satu kesempatan bagi Chihiro untuk menebak yang manakah orangtuanya di antara kumpulan babi tersebut. Jika benar, maka kedua orangtuanya bebas dari kutukan dan dapat kembali ke dunia manusia bersama dengan Chihiro yang juga bebas dari kontrak kerja. Berkat ikat rambut bermantera dari Zeniba, Chihiro bisa menjawab dengan yakin bahwa orangtuanya tidak ada di antara babi-babi tersebut. Dengan demikian, kontrak kerja Chihiro pun hangus dan ia bebas untuk kembali ke dunia manusia.

\section{Return with the Elixir}

Haku mengantarkan Chihiro hingga ke tepi padang rumput yang dilewatinya saat ia dan kedua orangtuanya tanpa sengaja memasuki dunia para arwah. Tanpa pengaruh sihir, Chihiro dapat kembali melihat padang rumput yang luas, bukan lautan sebagaimana saat ia masih berada di dunia para arwah.

Sesuai pesan Haku, Chihiro berjalan menyeberangi padang rumput menuju bangunan dengan terowongan sempit, tanpa menoleh ke belakang. Di sana, kedua orangtuanya yang sudah kembali dalam wujud manusia menunggu dengan cemas. Mereka berdua sama sekali tidak memiliki ingatan tentang apa yang pernah mereka alami di dunia para arwah. Kemudian, mereka bertiga berjalan menembus terowongan dan kembali ke dunia manusia, di tempat mobil mereka terparkir. Sempat terlintas dalam benak Chihiro untuk menoleh ke dalam terowongan, namun ikat rambut bermantera yang ia pakai tiba-tiba berkilau, dan saat itu juga Chihiro membatalkan niatnya untuk menengok ke belakang.

\section{SIMPULAN}

Dari hasil analisis, dapat diketahui bahwa tokoh utama Chihiro telah menjalani secara lengkap keduabelas tahapan perjalanan kepahlawanan sesuai dengan teori Hero's Journey milik Vogler. Petualangannya di dunia para arwah telah berhasil mengubah kepribadian Chihiro yang awalnya penakut, manja, dan cengeng menjadi pemberani, mandiri, tenang dan percaya diri, serta penuh belas kasih. Proses perjalanan kepahlawanan Chihiro ini membuktikan kebenaran definisi pahlawan menurut Vogler, sekaligus juga membuktikan bahwa untuk memenangkan sebuah 'pertarungan' tidak selalu menggunakan kekuatan fisik. Ada kalanya kecerdasan berpikir dan kecerdasan emosi justru jauh lebih dibutuhkan.

Selain menampilkan perjalanan kepahlawanan, anime Spirited Away juga banyak menampilkan kamisama. Dahulu yaoyorozu no kamigami dipercayai keberadaannya oleh bangsa Jepang, meskipun umumnya mereka tidak memiliki nama. Namun seiring dengan kemajuan zaman, kepercayaan tersebut sedikit demi sedikit memudar. Miyazaki mungkin ingin mengingatkan kembali mengenai keberadaan para dewa Jepang dan 'dunia lain' yang berdampingan dengan dunia manusia, dengan menampilkan mereka di dalam anime ini, baik yang benar-benar terdapat dalam mitologi Jepang maupun hasil kreasi Miyazaki sendiri. Dengan demikian, kisah Spirited Away yang memiliki struktur mitos seperti yang dikemukakan oleh Vogler menjadi jauh lebih hidup dan menarik.

\section{DAFTAR PUSTAKA}
Abrams, M. H. (1999). A Glossary of Literary Terms (7th ed.). Massachusetts: Heinle \& Heinle.

Allison, S. T., Goethals, G. R., \& Kramer, 
Izumi, Volume 8 No 1, 2019

e-ISSN: 2502-3535 p-ISSN: 2338-249X

Tersedia online di http://ejournal.undip.ac.id/index.php/izumi

R. M. (2017). Handbook of Heroism and Heroic Leadership. New York: Routledge.

Ashkenazi, M. (2003). Handbook of Japanese Mythology. California: ABC-CLIO, Inc.

Campbell, J. (2004). The Hero with a Thousand Faces (2nd ed.). New Jersey: Princeton University Press.

Emerson, D. (2009). Innocence as SuperPower: Little Girls on the Hero's Journey. Mythlore, 28(1-2), 131-148.

Miyazaki, H. (2001). Spirited Away. Japan: Studio Ghibli.

Nouri, Y. (2018). On Damsels and Heroines: A Comparative Study of the Hero's Journey in Little Red Riding Hood and Freeway. International Journal of Language and Literature, 5(2), 79-85. https://doi.org/10.15640/ijll.v5n2a8

Staemmler, B. (2016). Virtual Kamikakushi: An Element of Folk Belief in Changing Times and Media. Japanese Journal of Religious Studies, $32(2)$, 341-352. https://doi.org/10.18874/jjrs.32.2.200 5.341-352

Vogler, C. (2007). The Writer's Journey: Mythic Structure for Writers (3rd ed.). California: Michael Wiese Production. 